\title{
Adsorption and Photocatalytic Decomposition of the $\beta$-Blocker Metoprolol in Aqueous Titanium Dioxide Suspensions: Kinetics, Intermediates, and Degradation Pathways
}

\author{
Violette Romero, Pilar Marco, Jaime Giménez, and Santiago Esplugas \\ Department of Chemical Engineering, University of Barcelona, C/Martí i Franquès 1, 08028 Barcelona, Spain \\ Correspondence should be addressed to Pilar Marco; pmarco@ub.edu
}

Received 28 May 2013; Revised 25 September 2013; Accepted 3 October 2013

Academic Editor: Manickavachagam Muruganandham

Copyright (C) 2013 Violette Romero et al. This is an open access article distributed under the Creative Commons Attribution License, which permits unrestricted use, distribution, and reproduction in any medium, provided the original work is properly cited.

\begin{abstract}
This study reports the photocatalytic degradation of the $\beta$-blocker metoprolol (MET) using $\mathrm{TiO}_{2}$ suspended as catalyst. A series of photoexperiments were carried out by a UV lamp, emitting in the $250-400 \mathrm{~nm}$ range, providing information about the absorption of radiation in the photoreactor wall. The influence of the radiation wavelength on the MET photooxidation rate was investigated using a filter cutting out wavelengths shorter than $280 \mathrm{~nm}$. Effects of photolysis and adsorption at different initial $\mathrm{pH}$ were studied to evaluate noncatalytic degradation for this pharmaceutical. MET adsorption onto titania was fitted to two-parameter Langmuir isotherm. From adsorption results it appears that the photocatalytic degradation can occur mainly on the surface of $\mathrm{TiO}_{2}$. MET removed by photocatalysis was $100 \%$ conditions within $300 \mathrm{~min}$, while only $26 \%$ was achieved by photolysis at the same time. TiO photocatalysis degradation of MET in the first stage of the reaction followed approximately a pseudo-first-order model. The major reaction intermediates were identified by LC/MS analysis such as 3-(propan-2-ylamino)propane-1,2-diol or 3-aminoprop-1-en-2ol. Based on the identified intermediates, a photocatalytic degradation pathway was proposed, including the cleavage of side chain and the hydroxylation addition to the parent compounds.
\end{abstract}

\section{Introduction}

The presence of pharmaceutical drugs and endocrine disruptors in surface, ground, and drinking waters is a growing environmental concern [1-9]. This pollution is caused by emission from production sites, direct disposal of surplus drugs in households, excretion after drug administration to humans and animals, wastewater from fish and other animal farms, and industry $[3,10,11]$. Some of these drugs, as $\beta$ blockers, have been detected in the order of ng $\mathrm{L}^{-1}$ to $\mu \mathrm{g} \mathrm{L} \mathrm{L}^{-1}$ in the water [3-9, 12]. As an example, metoprolol tartrate salt (MET), which is usually prescribed as antihypertensive or antiarrhythmic, has been quantified up to $2 \mu \mathrm{g} \mathrm{L}^{-1}$ in sewage treatment plant (STP) effluents and to $240 \mathrm{ng} \mathrm{L}^{-1}$ in rivers [13]. Metoprolol and atenolol together account for more than $80 \%$ of total $\beta$-blockers consumption in Europe [6]. During the last years, metoprolol usage increased by a factor of 4 , probably due to a change in human behavior [6]. Although full ecotoxicity data are not available $[13,14]$, it has been shown that they can adversely affect aquatic organisms, even at low concentration [2]. Due to its widespread occurrence and potential impact, MET must be removed from treated water before discharge or reuse.

Several treatments for the removal of these compounds have been reported in the literature, including membrane filtration [15], activated carbon adsorption [16], and reverse osmosis $[17,18]$. However, the conventional water treatment processes are relatively inefficient in treating these compounds $[4,19]$. These pharmaceuticals can undergo abiotic degradation (hydrolysis, photolysis) [13] and most of them are photoactive because their structural compositions consist of aromatic rings, heteroatoms, and other functional groups that can absorb solar radiation [20]. Thus, sunlight induced photochemical treatments should be considered as an alternative to traditional treatment. Several researches have demonstrated that MET shows slow direct phototransformation and/or hydrolysis [13, 21, 22]. In this context, advanced oxidation processes (AOPs) appear as a good 


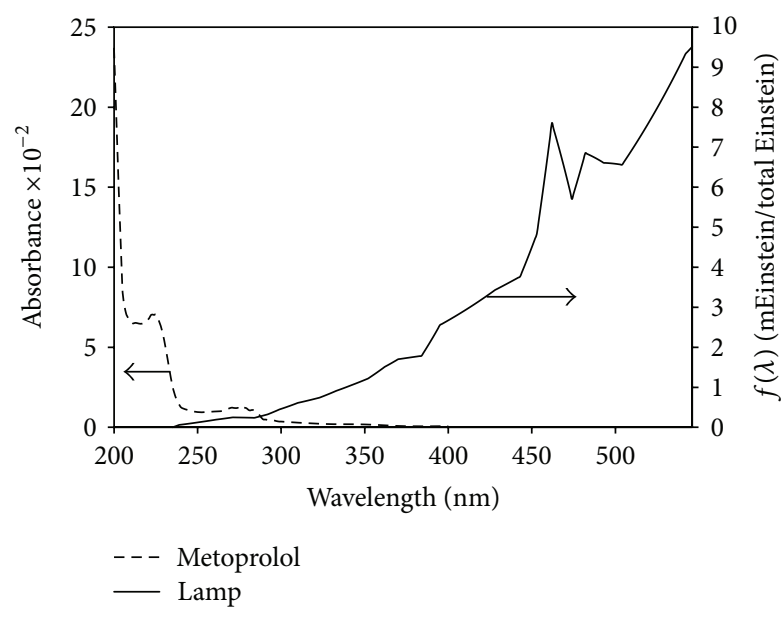

FIgURE 1: Absorbance spectrum of MET for aqueous concentration of $10 \mathrm{mg} \mathrm{L}^{-1}$ (left axis) and lamp spectrum (right axis), where $f(\lambda)$ represents the spectral distribution of the lamp.

alternative for its degradation due to their versatility and ability to increase biodegradability $[23,24]$. Among the different advanced oxidation processes, heterogenous photocatalysis has been a potential alternative for the degradation of hazardous pollutants. Oxidation of organic compounds by means of $\mathrm{TiO}_{2}$ was achieved by hydroxyl radical generation through the $e^{-} / h^{+}$pair generated when the semiconductor is exposed to UV radiation [11, 14].

The main objective of this investigation is to undertake a study on the heterogeneous photocatalytic degradation and mineralization of MET in aqueous suspensions with $\mathrm{TiO}_{2}$. In addition, the contribution of the degradation of MET by direct photolysis and the adsorption of the metoprolol onto $\mathrm{TiO}_{2}$ were studied. In this way, the effect of different initial $\mathrm{pH}$ values on the photodegradation rate and the adsorption isotherms of metoprolol in $\mathrm{TiO}_{2}$ suspensions were determined. The contribution of direct photolysis in photocatalysis was also examined in detail by using different wavelengths and glass type photoreactors. Additionally, an attempt has been completed to estimate the kinetic parameters and to identify the main intermediates formed during the photocatalytic degradation of MET.

\section{Materials and Methods}

2.1. Chemicals and Reagents. Metoprolol tartrate (MET) salt was purchased from Sigma Aldrich Chemical Co. (Spain) and used as received (1-[4-(2 methoxyethyl)phenoxy]-3-(propan2-ylamino)propan-2-ol tartrate (2:1), CAS no 56392-17-7, $\left(\mathrm{C}_{15} \mathrm{H}_{25} \mathrm{NO}_{3}\right)_{2} \mathrm{C}_{4} \mathrm{H}_{6} \mathrm{O}_{6}$, MW 684.81). Solutions of $50 \mathrm{mg} \mathrm{L}^{-1}$ of MET were prepared using deionized water to assure accurate measurements of concentrations, to follow the TOC, to secure identification of intermediates, and to make predictions about possible mechanisms of photocatalysis. For $\mathrm{pH}$ adjustment, $0.1 \mathrm{~mol} \mathrm{~L}^{-1}$ sulphuric acid or $0.1 \mathrm{~mol} \mathrm{~L}^{-1}$ sodium hydroxide was used. All chemicals were HPLC grade, and they were used without further purification. Titanium dioxide $\left(\mathrm{TiO}_{2}\right)$ Degussa P-25 (commercial catalyst $\sim 70 \%$ anatase, $\sim 30 \%$ rutile, surface area $50 \pm 5.0 \mathrm{~m}^{2} \mathrm{~g}^{-1}$, and $300 \mu \mathrm{m}$ particle size [25]) was used as received. This $\mathrm{TiO}_{2}$ is a photochemical stable material $[6,26,27]$.

2.2. Analytical Instruments. The target compounds concentrations were monitored by a high-performance liquid chromatograph (HPLC) from Waters using a SEA18 $5 \mu \mathrm{m}$ $15 \times 0.46$ Teknokroma column and Waters 996 photodiode array detector using Empower Pro software 2002 Water Co. The mobile phase was composed by water and acetonitrile $(20: 80)$, injected with a flow-rate of $0.85 \mathrm{~mL} \mathrm{~min}^{-1}$, and detected at maximum metoprolol $(221.9 \mathrm{~nm})$. Total organic carbon (TOC) was measured in a Shimadzu TOC-V CNS. $\mathrm{pH}$ was measured by a Crison GLP 22 instrument. UVVIS spectra of MET (Figure 1) were obtained for $10 \mathrm{mg} \mathrm{L}^{-1}$ aqueous solution on a PerkinElmer UV/vis Lambda 20 (200$400 \mathrm{~nm}$ range) spectrophotometer.

2.3. Experimental Procedure. Photodegradation experiments were conducted in a Solarbox (CO.FO.MEGRA, Milan, Italy) and equipped with a Xenon lamp (Phillips XOP, 1000W) and a tubular-horizontal photoreactor $(0.084 \mathrm{~L}$ illuminated volume) located at the axis of a parabolic mirror in the bottom of the Solarbox. The photon flux inside the photoreactor was evaluated by o-nitrobenzaldehyde actinometry [28, 29], being $2.68 \mu$ Einstein $\mathrm{s}^{-1}$. A stirred reservoir tank $(1.0 \mathrm{~L})$ was filled with the pharmaceutical- $\mathrm{TiO}_{2}$ (suspended) aqueous solution. The solution was continuously pumped (peristaltic pump Ecoline VC-280 II, Ismatec) to the equipment and recirculated to the reservoir tank with a flow of $0.65 \mathrm{~L} \mathrm{~min}^{-1}$. In order to keep the solution at $25^{\circ} \mathrm{C}$, the jacket temperature of the stirred tank was controlled with an ultrathermostat bath (Haake K10). Samples were taken every 30 minutes during 300 minutes and quickly analyzed. Before HPLC analysis, samples were filtered through $0.20 \mu \mathrm{m}$ PVDF membrane to separate $\mathrm{TiO}_{2}$. All the experiments were duplicated and the results presented were the mean values.

According to the literature [13], metoprolol stability in aqueous solution was previously verified, by storing $50 \mathrm{mg} \mathrm{L}^{-1}$ during 3 days in the dark at room temperature, and no degradation was observed.

MET adsorption of $\mathrm{TiO}_{2}$ was also measured. Thus, MET solution (0 to $50 \mathrm{mg} \mathrm{L}^{-1}$ ) was prepared with $\mathrm{TiO}_{2}$ in suspension $\left(0.4 \mathrm{~g} \mathrm{~L}^{-1}\right)$ and placed into $25 \mathrm{~mL}$ hermetic closed flasks, adjusting the $\mathrm{pH}$ with $\mathrm{NaOH}$ solution $\left(0.1 \mathrm{~mol} \mathrm{~L}^{-1}\right)$. The conical flasks were shaken at a constant speed of $100 \mathrm{rpm}$ and at room temperature $\left(25 \pm 0.5^{\circ} \mathrm{C}\right)$. Samples were taken every $24 \mathrm{~h}$, assuming that adsorption equilibrium was reached.

For the identification of byproducts, the final sample mixture, at 300 minutes, was analyzed by electrospray ionization/mass spectrometry using a PerSeptive, TOF Mariner Jascoo AS-2050 plus IS mass spectrometer into the $\mathrm{m} / \mathrm{z}$ range of 50-1000. The experiments were carried out in replicate. 


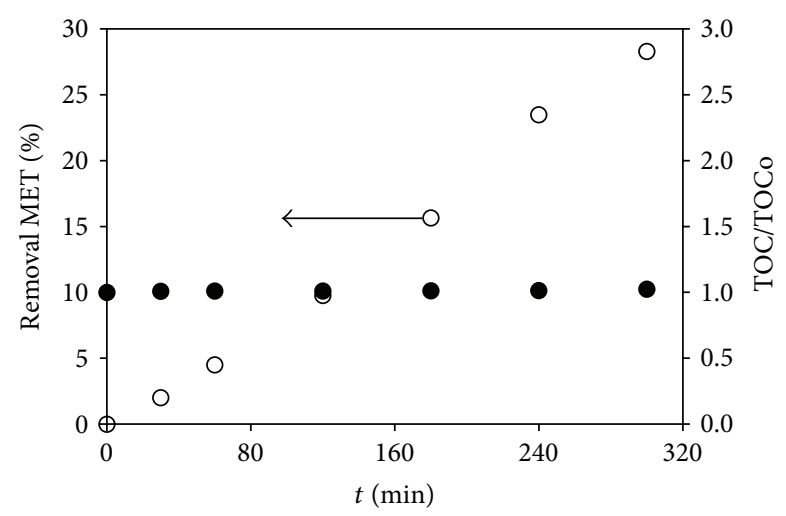

FIgURE 2: MET photodegradation removal (o) and TOC/TOCo (•) under simulated UV.

\section{Results and Discussion}

3.1. Effect of UV Radiation Photolysis on Metoprolol Degradation. When studying photocatalysis, it is very important to be able to separate the influence of photolysis, since it is expected to tackle the degradation of the substances mainly induced by the action of the catalyst. For this purpose, a series of experiments was done with UV illumination, and without catalyst to highlight the metoprolol ability to absorb the radiation reaching the system.

Figure 2 shows the results obtained after applying simulated sunlight. As observed, MET is not fast enough to be photodegraded in water by direct photolysis [30]; only $26 \%$ of MET in 300 minutes was degraded under simulated UV. Moreover, it shows that direct photolysis was not able to produce MET mineralization at the experimental conditions tested. This behavior can be explained because the MET absorption spectrum overlaps only slightly the spectrum of the incoming radiation (Figure 1).

The UV-VIS absorbance was used to calculate the molar absorption coefficient $(\varepsilon)$ of the metoprolol at a wavelength of $221.9 \mathrm{~nm}$ (Figure 1), assuming that Beer-Lambert's law is followed:

$$
A=-\log (T)=\varepsilon \times l \times C,
$$

where $A$ is the absorbance (measured directly by the spectrophotometer), $T$ is the transmittance, $\varepsilon$ is the molar absorption coefficient, $l$ is the distance that the light travels through the material, and $C$ is the concentration of pollutant. The molar absorption coefficient $(\varepsilon)$ was $281 \mathrm{~L} \mathrm{~mol}^{-1} \mathrm{~cm}^{-1}$; this value is very similar to other reported values $[12,13]$. This low value explains the MET stability in direct photolysis conditions. Nevertheless, different studies $[12,13,31]$ show a high photoability of some $\beta$-blockers, for example, propranolol, nadolol, and alprenolol. The rapid photodegradation of these compounds was supported by a high molecular absorption coefficient $\left(\varepsilon>800 \mathrm{~L} \mathrm{~mol}^{-1} \mathrm{~cm}^{-1}\right)$. This confirmed the hypothesis that photoinitiated reactions contribute to the degradation of naphthalene backbone (i.e., propranolol) [32], whereas the metoprolol, having a benzoic skeleton, is not sensitive to direct photolysis when dissolved in deionized water [33].

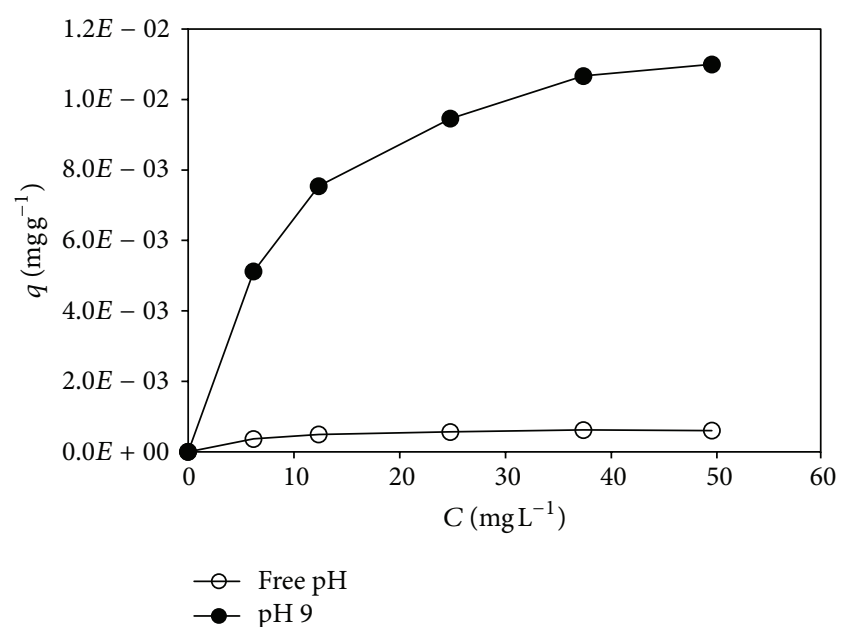

FIgURE 3: Effect of $\mathrm{pH}$ on adsorption of MET over $\mathrm{TiO}_{2}$ at $25^{\circ} \mathrm{C}, \mathrm{pH}$ $9(\bullet)$, and free $\mathrm{pH}(\mathrm{O})$.

The efficiency of the photochemical transformation process depends on many factors such as the irradiation setups, the characteristics of the light source, the water matrix used, the initial concentration, and the $\mathrm{pH}$ of the solutions [31]. Tests were carried out using different photoreactors, a borosilicate Duran, and quartz glass reactor, cutting out wavelengths shorter than 290 and $320 \mathrm{~nm}$, respectively. Other experiments have been done with and without glass filter for restricting transmissions of light below $280 \mathrm{~nm}$.

In this study, the effect of borosilicate Duran and quartz glass material reactor has been investigated under UV radiation. It was observed that MET removal was 25\% and $28 \%$ and the TOC reduction was $3.60 \%$ and $1.62 \%$, for reactors made with borosilicate Duran and quartz, respectively. Thus, although the mineralization was not significant, there is a small photodegradation of MET for the two tested reactors, after 300 minutes of reaction. Moreover, the effect of a filter glass cutting out wavelengths shorter than $280 \mathrm{~nm}$ has been investigated. As a result, only $19 \%$ of MET in 300 minutes has been removed with the glass filter; however, MET removal of $25 \%$ can be achieved without filter glass. TOC conversion was $6.37 \%$ and $3.60 \%$ with and without filter, correspondingly after 300 minutes, thus confirming that the mineralization is very low in both cases.

Summarizing, UV irradiation in the absence of $\mathrm{TiO}_{2}$ achieved an MET degradation lower than 30\% after 300 minutes of irradiation, confirming that the direct photolysis is not fast enough to be considered as an adequate technology.

3.2. The Role of the Adsorption on the Photocatalytic Degradation. Since the adsorption can play an important role in the evolution of the photodegradation, adsorption experiments at constant temperature $\left(25 \pm 0.5^{\circ} \mathrm{C}\right)$ were carried out. The adsorption capacity of MET, $q_{e}\left(\mathrm{mg} \mathrm{g}^{-1}\right)$, was calculated from the difference in MET concentration in the aqueous phase before and after adsorption at different initial MET concentrations $\left(0,6.2,12.5,25,37.5\right.$, and $\left.50 \mathrm{mg} \mathrm{L}^{-1}\right)$. The variation in adsorption of MET onto $\mathrm{TiO}_{2}$ was studied at two pHs: 9 and free $\mathrm{pH}(\mathrm{pH} \approx 5.8)$. Figure 3 presents the obtained 
TABLE 1: Isotherm parameters for MET adsorption onto $\mathrm{TiO}_{2}$ obtained by linear method at $25^{\circ} \mathrm{C}$.

\begin{tabular}{|c|c|c|c|}
\hline \multirow{2}{*}{ Two-parameter model } & \multirow{2}{*}{ Parameters } & \multicolumn{2}{|c|}{$\mathrm{pH}$} \\
\hline & & Free & 9 \\
\hline \multirow{3}{*}{$\begin{array}{l}\text { Langmuir } \\
q_{e}=\frac{q_{m} K_{a} C_{e}}{1+K_{a} C_{e}}\end{array}$} & $q_{m}\left(\mathrm{~mol} \mathrm{~g}^{-1}\right)$ & 0.0014 & 0.0250 \\
\hline & $K_{L}\left(\mathrm{~L} \mathrm{~mol}^{-1}\right)$ & 0.0930 & 0.0817 \\
\hline & $R^{2}$ & 0.987 & 0.998 \\
\hline \multirow{3}{*}{$\begin{array}{l}\text { Freundlich } \\
q_{e}=K_{F} C_{e}^{1 / n}\end{array}$} & $1 / n$ & 0.244 & 0.670 \\
\hline & $K_{F}\left(\mathrm{~L} \mathrm{~mol}^{-1}\right)$ & 0.00042 & 0.00129 \\
\hline & $R^{2}$ & 0.105 & 0.147 \\
\hline \multirow{3}{*}{$\begin{array}{l}\text { Temkin } \\
q_{e}=\frac{R T}{b} \ln \left(K_{T}+C_{e}\right)\end{array}$} & $R T / b$ & 0.00024 & 0.00508 \\
\hline & $K_{T}\left(\mathrm{~L} \mathrm{~mol}^{-1}\right)$ & 2.718 & 0.962 \\
\hline & $R^{2}$ & 0.604 & 0.982 \\
\hline \multirow{3}{*}{$\begin{array}{l}\text { Dubinin-Radushkevich } \\
q_{e}=q_{D} \exp \left(-B_{d}\left[R T \ln \left(1+\frac{1}{C_{e}}\right)\right]\right)\end{array}$} & $q_{D}\left(\mathrm{molg}^{-1}\right)$ & 0.0013 & 0.0233 \\
\hline & $B_{D} \times 10^{-3}\left(\mathrm{~mol}^{2} \mathrm{~kJ}^{-2}\right)$ & 1.533 & 1.532 \\
\hline & $R^{2}$ & 0.835 & 0.778 \\
\hline \multicolumn{4}{|l|}{ Three-parameter model } \\
\hline \multirow{4}{*}{$\begin{array}{l}\text { Redlich-Peterson } \\
q_{e}=\frac{K_{\mathrm{RP}} C_{e}}{1+a_{R} C_{e}^{\beta}}\end{array}$} & $K_{\mathrm{RP}}\left(\mathrm{L} \mathrm{mol}^{-1}\right)$ & 0.00011 & 0.10 \\
\hline & $a_{R}\left(\mathrm{~L} \mathrm{~mol}^{-1}\right)$ & 0.051 & 18.040 \\
\hline & $\beta$ & 0.999 & 0.679 \\
\hline & $R^{2}$ & 0.826 & 0.789 \\
\hline \multirow{4}{*}{$\begin{array}{l}\text { Langmuir-Freundlich } \\
q_{e}=\frac{K_{\mathrm{LF}} C_{e}^{n_{\mathrm{LF}}}}{1+\left(a_{\mathrm{LF}} C_{e}\right)^{n_{\mathrm{LF}}}}\end{array}$} & $K_{\mathrm{LF}}\left(\mathrm{L} \mathrm{mol}^{-1}\right)$ & 0.000205 & 0.00809 \\
\hline & $a_{\mathrm{LF}}\left(\mathrm{L} \mathrm{mol}^{-1}\right)$ & 0.134 & 0.310 \\
\hline & $n_{\mathrm{LF}}$ & 0.779 & 0.92 \\
\hline & $R^{2}$ & 0.211 & 0.734 \\
\hline
\end{tabular}

results and indicates that the amount adsorbed increases when $\mathrm{pH}$ does it.

The increase in the adsorption of metoprolol with increasing $\mathrm{pH}$ can be elucidated by considering the surface charge of the adsorbent material $\left(\mathrm{pH}_{\mathrm{pzc}} \sim 6.5\right)[13,34]$. That is, titanium dioxide surface is positively charged in acid media $\mathrm{pH}(\mathrm{pH} \leq$ 7) whereas it is negatively charged under alkaline conditions $(\mathrm{pH} \geq 7)[29,35]$. Also, metoprolol can be transformed to MET anion in the basic $\mathrm{pH}(\mathrm{pH} \sim 10)$ since the $\mathrm{pK}_{\mathrm{a}}$ value of metoprolol is 9.7 [36]. Under free $\mathrm{pH}$ conditions, close to the point zero charge of $\mathrm{TiO}_{2}$ (6.5) [30], MET is positively charged. A low adsorption was observed due to no electrostatic attraction between the surface charge and MET. A highest adsorption between MET and $\mathrm{TiO}_{2}$ would be observed at $\mathrm{pH} \mathrm{9}$, because the negative charges of the surface of the catalyst attract the protonated MET form. In addition the photocatalytic degradation would be expected on the surface of the catalysis.

Two-parameter isotherm models (Langmuir, Freundlich, Temkin, and Dubinin-Radushkevich) and three-parameter isotherm models (Redlich-Peterson and LangmuirFreundlich) were tested in the fitting of the adsorption data of MET onto titanium dioxide $[37,38]$.

$K_{a}, K_{F}, K_{T}, K_{\mathrm{RP}}$, and $K_{L}$ are the Langmuir, Freundlich, Temkin, Redlich-Peterson and Langmuir-Freundlich adsorption equilibrium constants $\left(\mathrm{L} \mathrm{mol}^{-1}\right)$, respectively; $a_{R}$ and $a_{\mathrm{LF}}$ are also the Redlich-Peterson and Langmuir-Freundlcih constants $\left(\mathrm{L} \mathrm{mol}^{-1}\right)$, respectively; $C_{e}$ and $q_{e}$ are the equilibrium concentration $\left(\mathrm{mol} \mathrm{L}^{-1}\right)$ and the adsorption capacity $\left(\mathrm{molg}^{-1}\right)$, respectively; $q_{D}$ is the Dubinin-Radushkevich saturation capacity $\left(\mathrm{mol} \mathrm{g}^{-1}\right)$. The parameter $q_{m}$ represents the maximum monolayer adsorption capacity $\left(\mathrm{mol} \mathrm{g}^{-1}\right)$ and $1 / n$ the adsorption intensity, which provides an indication of favorability and capacity of the adsorbent/adsorbate system. The parameter $b$ is related to the adsorption heat; $B_{D}$ gives the mean adsorption free energy $E_{D}\left(\mathrm{~kJ} \mathrm{~mol}^{-1}\right)$. The parameters $\beta$ and $n_{\mathrm{LF}}$ are the Redlich-Peterson and Langmuir-Freundlich exponents which lie between 0 and 1 [39]. And $R^{2}$ is the corresponding sum of squares error obtained in the fitting experimental data of each model.

From Table 1, it was observed that the best fitting were obtained for Langmuir isotherm $\left(R^{2}=0.987\right.$ and 0.998 for free $\mathrm{pH}$ and $\mathrm{pH} 9$, respectively). Thus, these models represent the equilibrium adsorption of $\mathrm{MET}$ on $\mathrm{TiO}_{2}$ particles in the range of concentration studied. Accordingly, the adsorption mechanism may be interpreted as a monolayer coverage of the catalyst surface.

For free $\mathrm{pH}$ MET adsorption $\left(q_{m}\right)$ was lower than for $\mathrm{pH}$ 9, $0.0014 \mathrm{~mol} \mathrm{~g}^{-1}$, and $0.0250 \mathrm{~mol} \mathrm{~g}^{-1}$, respectively. In these cases, the adsorption does not play an important role in the photocatalytic process. The MET percentage removal in dark conditions was $0.1 \%$ and $11 \%$ for free $\mathrm{pH}$ and $\mathrm{pH}$ 9. These low adsorption values and MET percentage removals suggest that 
TABLE 2: Kinetics of metoprolol UV-C photodegradation under different conditions.

\begin{tabular}{|c|c|c|c|c|}
\hline & Glass material reactor & Glass filter $\lambda \geq 280 \mathrm{~nm}$ & $\mathrm{pH}$ & $t_{1 / 2}(\mathrm{~h})$ \\
\hline \multirow{3}{*}{ Photolysis } & \multirow{2}{*}{ Borosilicate } & with & $5.8 \pm 1$ & $16.5 \pm 0.5$ \\
\hline & & without & $5.8 \pm 1$ & $11.6 \pm 0.6$ \\
\hline & Quartz & without & $5.8 \pm 1$ & $10.5 \pm 0.5$ \\
\hline \multirow{2}{*}{ Photocatalysis } & \multirow{2}{*}{ Borosilicate } & without & $5.8 \pm 1$ & $0.81 \pm 0.4$ \\
\hline & & without & $9.0 \pm 1$ & $0.58 \pm 0.3$ \\
\hline
\end{tabular}

the most possible way of degradation could be reached by migration of $\bullet \mathrm{OH}$ radicals to the bulk of the suspension.

3.3. Degradation of MET by Photocatalytic Process. The photocatalytic degradation of MET solution $\left(50 \mathrm{mg} \mathrm{L}^{-1}\right)$ was carried out during 300 minutes, in the presence of $0.4 \mathrm{~g} \mathrm{~L}^{-1}$ of $\mathrm{TiO}_{2}$ under UV-VIS light at room temperature. It is know that, in heterogeneous photocatalysis, the rate of degradation is not always proportional to the catalyst load [40]. An optimal point exists where $\mathrm{TiO}_{2}$ loaded shows a maximum degradation rate. Previous studies carried out in our research group reported that the optimum catalyst concentration was $0.4 \mathrm{gL}^{-1}$ [41]. Over this value, scattering can appear, and therefore increase in degradation rate does not occur.

Firstly, the solution mixture was stirred for 24 hours without irradiation in order to get the equilibrium of MET adsorption.

Figure 4 depicts the photocatalytic degradation of MET at free $\mathrm{pH}$ and $\mathrm{pH}$ 9. Maximum conversions are achieved at 240 and 300 minutes for $\mathrm{pH} 9$ and free $\mathrm{pH}$, respectively. An important remark is that the initial removal rate for free $\mathrm{pH}$ and $\mathrm{pH} 9$ experiments is different, being higher at $\mathrm{pH}$ 9. The effect of $\mathrm{pH}$ on the conversion is a complex issue related to the ionization states of the catalyst surface and the substrate, as well as the rate of formation of radicals and other reactive species in the reaction mixture [42]. These effects can be assessed since the action of the holes is favored at acidic conditions, while hydroxyl radicals become the dominant species at neutral and alkaline conditions [42].

As known, photocatalysis occurs through the energy adsorption by the catalyst (light between 200 and $400 \mathrm{~nm}$ for $\mathrm{TiO}_{2}$ ). Under excited condition, the valance band-electron is transferred to the conduction band forming the hole-electron pair $\left(h^{+} / e^{-}\right)(2)$. The hydroxyl radicals are formed by cleavage of adsorbed molecules of water [43]:

$$
\begin{gathered}
\mathrm{TiO}_{2}+h \gamma \longrightarrow \mathrm{TiO}_{2}^{*}\left(\frac{h^{+}}{e^{-}}\right) \\
h^{+}+\mathrm{H}_{2} \mathrm{O} \longrightarrow \cdot \mathrm{OH}+\mathrm{H}^{+}
\end{gathered}
$$

If organic compounds are absorbed on the surface of the catalyst, the $\bullet \mathrm{OH}$ nonselective attack promotes the cleavage of compounds bounds. The higher MET degradation and the low MET adsorption on catalyst at a $\mathrm{pH} 9$ suggest that the - $\mathrm{OH}$ attack in the bulk of solution can be responsible for the MET degradation [40, 44].

The values of TOC during the photocatalytic degradation of MET, at two different pHs, are given in Figure 4. The TOC
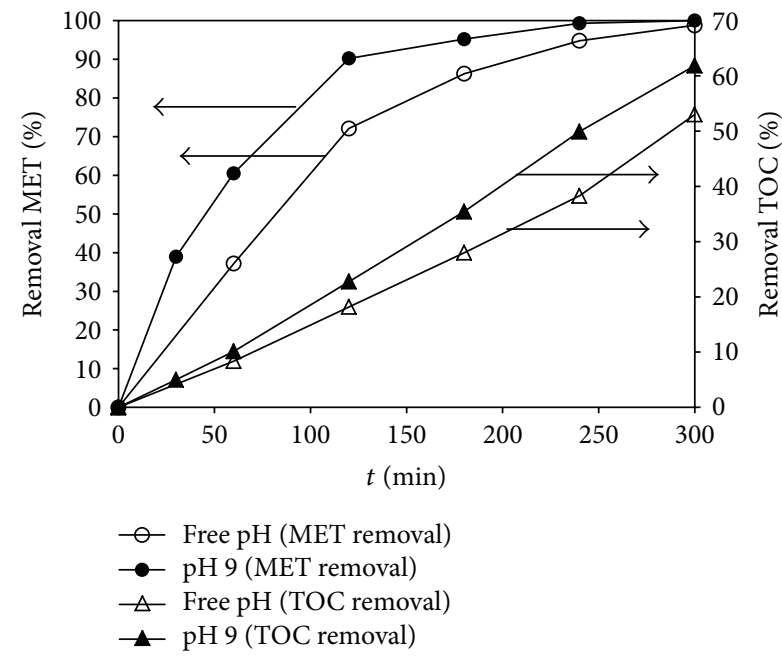

FIGURE 4: MET and TOC removal (\%) versus time (min) at free $\mathrm{pH}$ and $\mathrm{pH} 9$ in photocatalytic experiments.

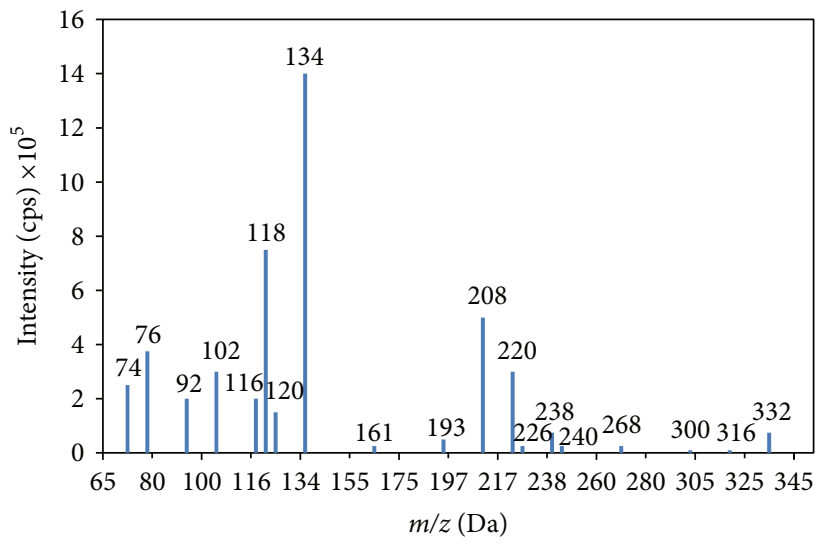

FIGURE 5: MS spectrum of major oxidation products of metoprolol.

increases with time, indicating the increasing mineralization of the initial organic structures.

3.4. Kinetics of MET Degradation. The Langmuir-Hinshelwood $(\mathrm{L}-\mathrm{H})$ model is usually used to describe the kinetics of photocatalytic degradation of organic pollutants $[12,13,30$, $31,41,45$ ], being the kinetic equation expressed as

$$
r=-\frac{d C}{d t}=\frac{K_{\mathrm{ads}} \cdot k_{\mathrm{H}-\mathrm{L}} \cdot C}{1+K_{\mathrm{ads}} \cdot C}
$$


TABLE 3: Intermediates proposed for the photocatalytic degradation of MET.

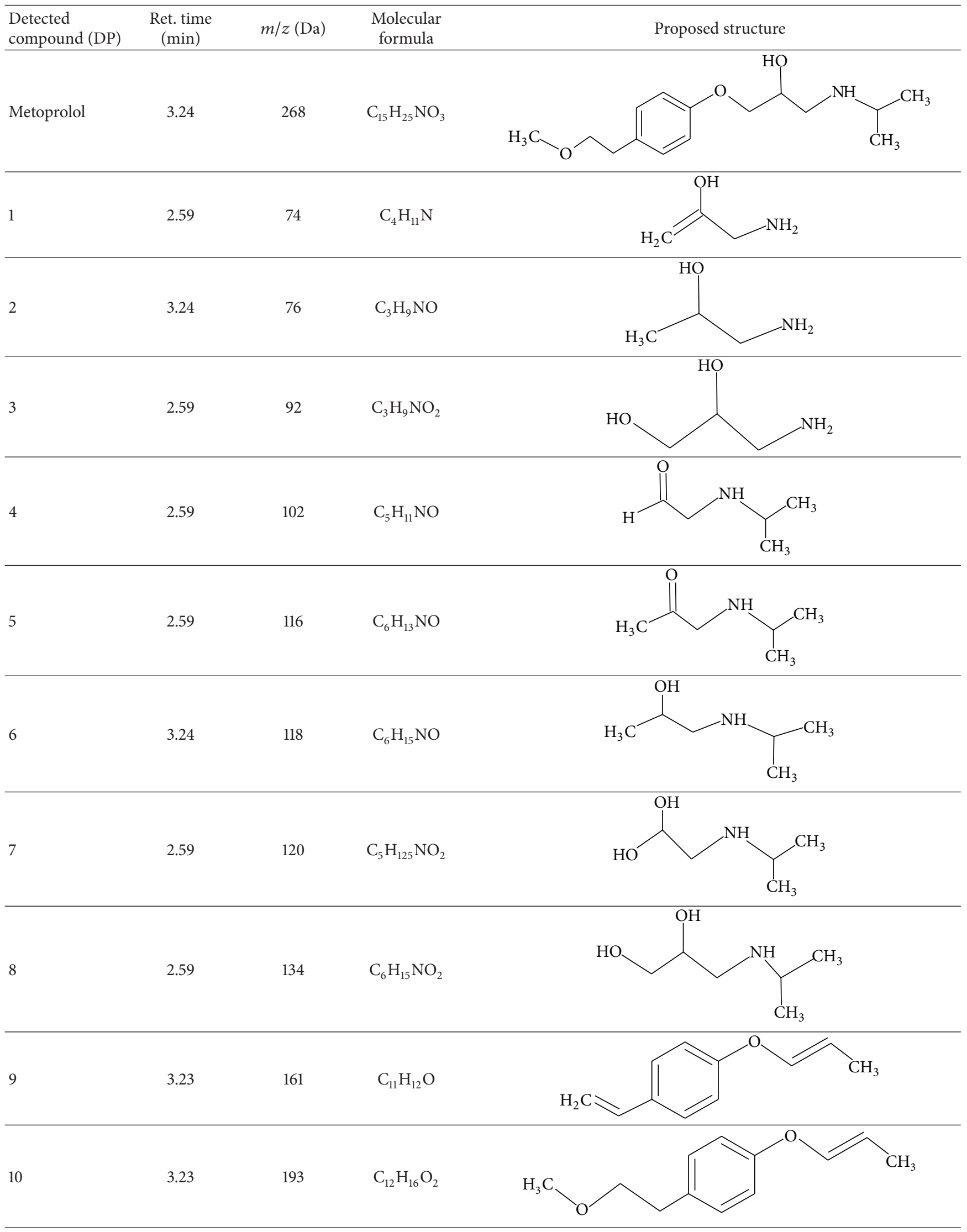


TABle 3: Continued.

$\begin{array}{lccc}\begin{array}{l}\text { Detected } \\ \text { compound (DP) }\end{array} & \begin{array}{c}\text { Ret. time } \\ (\mathrm{min})\end{array} & \mathrm{m} / z(\mathrm{Da}) & \begin{array}{c}\text { Molecular } \\ \text { formula }\end{array} \\ 3.24 & 208 & \end{array}$

13

3.03

4.71

238

$\mathrm{C}_{13} \mathrm{H}_{19} \mathrm{NO}_{3}$

$\mathrm{C}_{12} \mathrm{H}_{19} \mathrm{NO}_{3}$

14

226

$\mathrm{C}_{12} \mathrm{H}_{19} \mathrm{NO}_{3}$<smiles>COCCc1ccc(OCC(O)CN)cc1</smiles><smiles>COc1ccc(C=O)cc1</smiles><smiles>CC(C)CNC(C)C</smiles>

$\mathrm{O}$

15

3.23

240

$\mathrm{C}_{13} \mathrm{H}_{21} \mathrm{NO}_{3}$<smiles>CC(C)NCC(O)COc1ccc(CO)cc1</smiles>

162300

where $r$ is the degradation rate, $C$ is the reactant concentration, $t$ is the time, $k_{\mathrm{H}-\mathrm{L}}$ is the rate constant, and $K_{\mathrm{ad}}$ is the adsorption equilibrium constant.

This model assumes that adsorption is a rapid equilibrium process and that the rate-determining step of the reaction involves the species present in a monolayer at the solid-liquid interface. Furthermore if the adsorption of MET onto the surface of the photocatalysts is very low, $K_{\text {ads }} \cdot C$ can be neglected in the denominator simplifying the equation to a pseudo-first-order equation as given by [46]

$$
r=-\frac{d C}{d t}=K_{\mathrm{ads}} \cdot k_{\mathrm{H}-\mathrm{L}} \cdot C=k \cdot C
$$




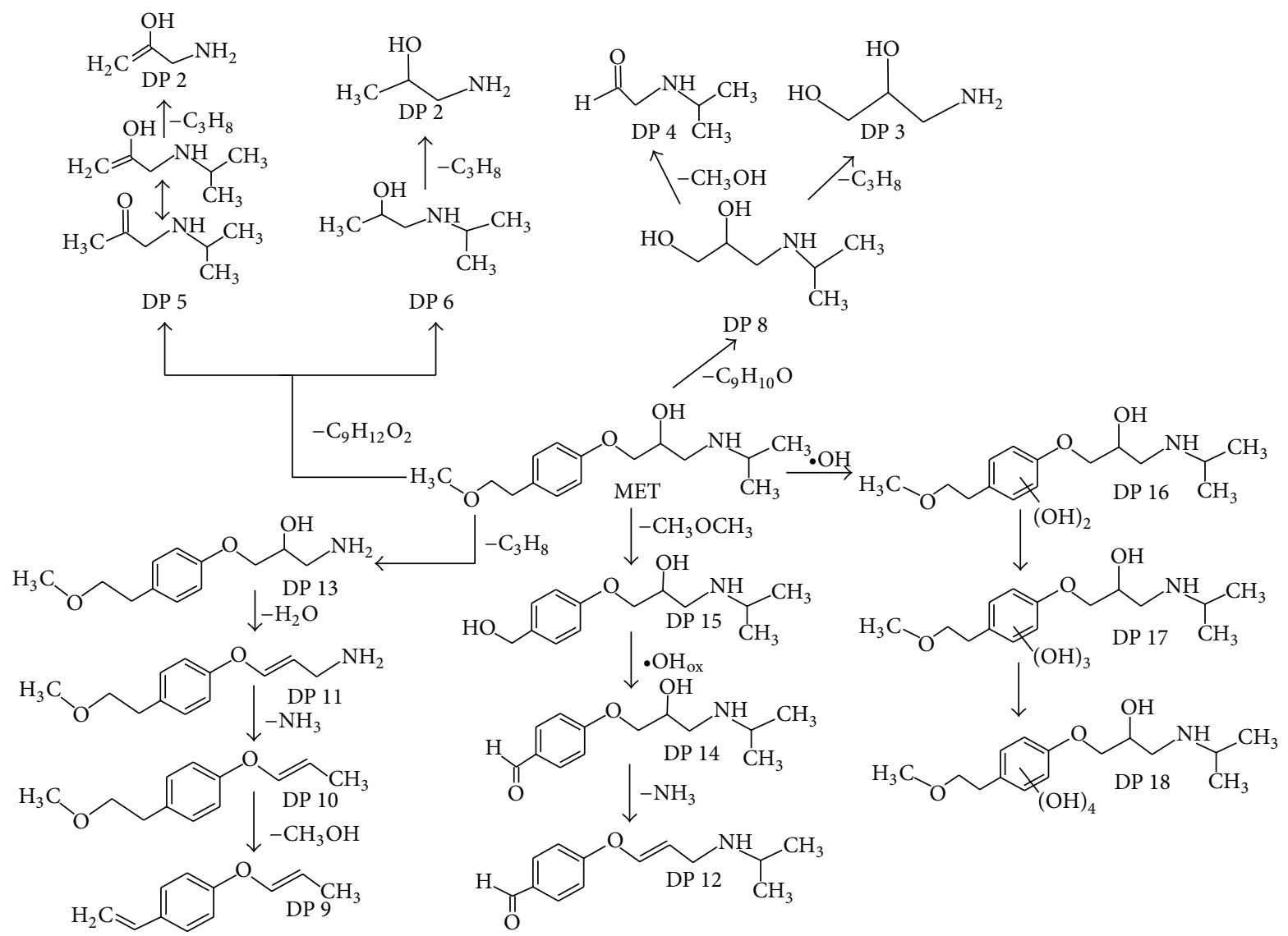

FIGURE 6: Proposed pathways for the degradation of MET.

The integrated form of the above equation is represented by

$$
\ln \left(\frac{C_{o}}{C}\right)=k_{\text {app }} \cdot t
$$

where $C_{0}$ is the initial pollutant concentration and $k_{\text {app }}$ is the apparent pseudo-first-order reaction rate constant.

The half-life was calculated with the following expression:

$$
t_{1 / 2}=\frac{\ln 2}{k} .
$$

The values of $t_{1 / 2}$ in Table 2 verify that the direct photolysis under simulated light was very low. The low photodegradation of MET was also supported by a low molar absorption coefficient $\left(281 \mathrm{~L} \mathrm{~mol}^{-1} \mathrm{~cm}^{-1}\right)$ measured at $221.9 \mathrm{~nm}$ wavelength. However, an important increasing difference is observed in the MET degradation when $\mathrm{TiO}_{2}$ is present. Also, when photocatalytic process is applied, results in TOC conversion (63\%) are notoriously improved, for initial concentration of $50 \mathrm{mg} \mathrm{L}^{-1}$ of MET and $0.4 \mathrm{~g} \mathrm{~L}^{-1}$ of catalyst.

If both processes are compared, photocatalytic process is always much faster than the photolytic degradation of MET. Therefore, the interest of using photocatalysis in the treatment of this type of pollutant is obvious.

3.5. Intermediates during Reaction. The major by-products formed during 6 hours of photocatalytic treatment of MET were identified (Figure 5). The study was carried out using HPLC/MS in positive electrospray model. The degradation intermediates for MET are shown in Table 3.

The metoprolol has a molecular weight $[\mathrm{M}+\mathrm{H}+]=268$. Three intermediates corresponding to the binding of $\bullet \mathrm{OH}$ radicals in the aromatic ring were detected at $m / z 300,316$, and 332, di-(DP (Detected Compound) 16), tri-(DP 17), and tetrahydroxy (DP 18) DPs, respectively. After breaking the C$\mathrm{C}$ bond in the aliphatic part of the MET molecule, amino-diol (DP 8) was identified as one of the dominant intermediates with $m / z=134$. Different fragments of the ethanolamine side were also identified (DP 1, DP 2, DP 3, DP 4, DP 5, DP 6, and DP 7), probably due to the loss of the hydroxyl group and the loss of isopropyl moiety.

PD 15 can be formed probably by reactions which involve attack on the ether side chain followed by elimination. On the other hand, the oxidation of alcohols to aldehydes can be explained by the formation of DP 14 with $\mathrm{m} / z=238$ [47]. The hydrogen abstraction and the water elimination of DP 14 probably generate a carbonyl, followed by an intermolecular electron transfer; it generates a double bond and the consequent formation of DP 12.

Oxidative attack on the dimethylamine moiety results in a DP 13 with $m / z=226$. Following this, the hydrogen abstraction and elimination of water of DP 13 generate a carbonyl which followed by intermolecular electron transference, generates a double bond and forming DP 11. The DP 
11 can generate DP 10 corresponding to a loss of ammonia after the hydrogen abstraction. The intermediate 9 could be formed by the loss of methanol combined with the attack of - $\mathrm{OH}$ on the $\mathrm{C}$ atom next to the ether oxygen in the aliphatic part of DP 10.

A simplified fragmentation pathway of metoprolol degradation is shown in Figure 6.

\section{Conclusions}

Langmuir isotherm fits very well the experimental data, which indicates that the adsorption of the MET onto $\mathrm{TiO}_{2}$ is by monolayer coverage of the catalyst surface. The results confirmed that the degradation of MET is not able to undergo by direct photolysis due to its lower absorption coefficient. In contrast, the addition of $\mathrm{TiO}_{2}$ photocatalyst significantly increases its degradation rate and, after $240 \mathrm{~min}$ of irradiation, MET was totally eliminated for $\mathrm{pH}$ 9. The experimental data indicates that $\mathrm{TiO}_{2}$ photocatalysis allows a fast and efficient removal of metoprolol, transforming substrate into by-products that are more difficult to be degraded by photocatalysis, as evidenced by the level of mineralization achieved (63\%). Disappearance of MET by photocatalysis follows Langmuir-Hinshelwood model that can be simplified as a pseudo-first-order equation, as usually found in heterogenous photocatalysis at low concentration. Photocatalytic degradation rate of MET depends on $\mathrm{pH}$, occurring the faster degradation at $\mathrm{pH}$ 9. At last, based on the identified degradation intermediates at 6-hour reaction time, a photocatalytic degradation pathway of metoprolol was proposed. The main pathways involved in the photocatalytic degradation process include hydroxilation of the aromatic ring, shortening of methoxyl contained in the lateral chain, and cleavage of or addition of $\bullet \mathrm{OH}$ to the amine lateral chain.

\section{Acknowledgments}

The authors are grateful to CICYT Project CTQ2011-26258, Consolider-Ingenio NOVEDAR 2010 CSD2007-00055, and AGAUR, Generalitat de Catalunya (Project 200956R 1466) for funds received to carry out this work.

\section{References}

[1] A. Pal, K. Y.-H. Gin, A. Y.-C. Lin, and M. Reinhard, "Impacts of emerging organic contaminants on freshwater resources: review of recent occurrences, sources, fate and effects," Science of the Total Environment, vol. 408, no. 24, pp. 6062-6069, 2010.

[2] Y. Xu, T. V. Nguyen, M. Reinhard, and K. Y.-H. Gin, "Photodegradation kinetics of p-tert-octylphenol, 4-tertoctylphenoxy-acetic acid and ibuprofen under simulated solar conditions in surface water," Chemosphere, vol. 85, no. 5, pp. 790-796, 2011.

[3] A. Jurado, E. Vàzquez-Suñé, J. Carrera, M. López de Alda, E. Pujades, and D. Barceló, "Emerging organic contaminants in groundwater in Spain: a review of sources, recent occurrence and fate in a European context," Science of the Total Environment, vol. 440, pp. 82-94, 2012.
[4] M. Huerta-Fontela, M. T. Galceran, and F. Ventura, "Occurrence and removal of pharmaceuticals and hormones through drinking water treatment," Water Research, vol. 45, no. 3, pp. 1432-1442, 2011.

[5] M. Pedrouzo, F. Borrull, E. Pocurull, and R. M. Marcé, "Presence of pharmaceuticals and hormones in waters from sewage treatment plants," Water, Air, and Soil Pollution, vol. 217, no. 1-4, pp. 267-281, 2011.

[6] A. C. Alder, C. Schaffner, M. Majewsky, J. Klasmeier, and K. Fenner, "Fate of $\beta$-blocker human pharmaceuticals in surface water: comparison of measured and simulated concentrations in the Glatt Valley Watershed, Switzerland," Water Research, vol. 44, no. 3, pp. 936-948, 2010.

[7] M. Maurer, B. I. Escher, P. Richle, C. Schaffner, and A. C. Alder, "Elimination of $\beta$-blockers in sewage treatment plants," Water Research, vol. 41, no. 7, pp. 1614-1622, 2007.

[8] B. Abramović, S. Kler, D. Šojić, M. Laušević, T. Radović, and D. Vione, "Photocatalytic degradation of metoprolol tartrate in suspensions of two $\mathrm{TiO}_{2}$-based photocatalysts with different surface area. Identification of intermediates and proposal of degradation pathways," Journal of Hazardous Materials, vol. 198, pp. 123-132, 2011.

[9] M. Maurer, B. I. Escher, P. Richle, C. Schaffner, and A. C. Alder, "Elimination of $\beta$-blockers in sewage treatment plants," Water Research, vol. 41, no. 7, pp. 1614-1622, 2007.

[10] E. Isarain-Chávez, J. A. Garrido, R. M. Rodríguez et al., "Mineralization of metoprolol by electro-fenton and photoelectrofenton processes," Journal of Physical Chemistry A, vol. 115, no. 7, pp. 1234-1242, 2011.

[11] L. Prieto-Rodríguez, I. Oller, N. Klamerth, A. Agüera, E. M. Rodríguez, and S. Malato, "Application of solar AOPs and ozonation for elimination of micropollutants in municipal wastewater treatment plant effluents," Water Research, vol. 47, pp. 1521-1528, 2013.

[12] I. Kim and H. Tanaka, "Photodegradation characteristics of PPCPs in water with UV treatment," Environment International, vol. 35, no. 5, pp. 793-802, 2009.

[13] A. Piram, A. Salvador, C. Verne, B. Herbreteau, and R. Faure, "Photolysis of $\beta$-blockers in environmental waters," Chemosphere, vol. 73, no. 8, pp. 1265-1271, 2008.

[14] H. Fang, Y. Gao, G. Li et al., "Advanced oxidation kinetics and mechanism of preservative propylparaben degradation in aqueous suspension of $\mathrm{TiO}_{2}$ and risk assessment of its degradation products," Environmental Science and Technology, vol. 47, pp. 2704-2712, 2013.

[15] L. D. Nghiem, A. I. Schäfer, and M. Elimelech, "Pharmaceutical retention mechanisms by nanofiltration membranes," Environmental Science and Technology, vol. 39, no. 19, pp. 7698-7705, 2005.

[16] T. Heberer, "Occurrence, fate, and removal of pharmaceutical residues in the aquatic environment: a review of recent research data," Toxicology Letters, vol. 131, no. 1-2, pp. 5-17, 2002.

[17] C. Hartig, M. Ernst, and M. Jekel, "Membrane filtration of two sulphonamides in tertiary effluents and subsequent adsorption on activated carbon," Water Research, vol. 35, no. 16, pp. 39984003, 2001.

[18] J. Radjenović, M. Petrović, F. Ventura, and D. Barceló, "Rejection of pharmaceuticals in nanofiltration and reverse osmosis membrane drinking water treatment," Water Research, vol. 42, no. 14, pp. 3601-3610, 2008. 
[19] P. Westerhoff, Y. Yoon, S. Snyder, and E. Wert, "Fate of endocrine-disruptor, pharmaceutical, and personal care product chemicals during simulated drinking water treatment processes," Environmental Science and Technology, vol. 39, no. 17, pp. 6649-6663, 2005.

[20] J. Peuravuori and K. Pihlaja, "Phototransformations of selected pharmaceuticals under low-energy UVA-vis and powerful UVB-UVA irradiations in aqueous solutions-the role of natural dissolved organic chromophoric material," Analytical and Bioanalytical Chemistry, vol. 394, no. 6, pp. 1621-1636, 2009.

[21] Q.-T. Liu, R. I. Cumming, and A. D. Sharpe, "Photo-induced environmental depletion processes of $\beta$-blockers in river waters," Photochemical and Photobiological Sciences, vol. 8, no. 6, pp. 768-777, 2009.

[22] Q.-T. Liu, R. I. Cumming, and A. D. Sharpe, "Photo-induced environmental depletion processes of $\beta$-blockers in river waters," Photochemical and Photobiological Sciences, vol. 8, no. 6, pp. 768-777, 2009.

[23] R. Molinari, F. Pirillo, V. Loddo, and L. Palmisano, "Heterogeneous photocatalytic degradation of pharmaceuticals in water by using polycrystalline $\mathrm{TiO}_{2}$ and a nanofiltration membrane reactor," Catalysis Today, vol. 118, no. 1-2, pp. 205-213, 2006.

[24] W. Song, W. J. Cooper, S. P. Mezyk, J. Greaves, and B. M. Peake, "Free radical destruction of $\beta$-blockers in aqueous solution," Environmental Science and Technology, vol. 42, no. 4, pp. 12561261, 2008.

[25] M. Janus, J. Choina, and A. W. Morawski, "Azo dyes decomposition on new nitrogen-modified anatase $\mathrm{TiO}_{2}$ with high adsorptivity," Journal of Hazardous Materials, vol. 166, no. 1, pp. $1-5,2009$.

[26] T. E. Doll and F. H. Frimmel, "Fate of pharmaceuticalsphotodegradation by simulated solar UV-light," Chemosphere, vol. 52, no. 10, pp. 1757-1769, 2003.

[27] M. Šcepanovic, B. Abramovic, A. Golubovic et al., "Photocatalytic degradation of metoprolol in water suspension of $\mathrm{TiO}_{2}$ nanopowders prepared using sol-gel route," Journal of Sol-Gel Science and Technology, vol. 61, pp. 390-402, 2012.

[28] K. L. Willett and R. A. Hites, "Chemical actinometry: using oNitrobenzaldehyde to measure light intensity in photochemical experiments," Journal of Chemical Education, vol. 77, no. 7, pp. 900-902, 2000.

[29] N. De la Cruz, V. Romero, R. F. Dantas et al., "oNitrobenzaldehyde actinometry in the presence of suspended $\mathrm{TiO}_{2}$ for photocatalytic reactors," Catalysis Today, vol. 209, pp. 209-214, 2013.

[30] F. J. Rivas, O. Gimeno, T. Borralho, and M. Carbajo, "UV-C radiation based methods for aqueous metoprolol elimination," Journal of Hazardous Materials, vol. 179, no. 1-3, pp. 357-362, 2010.

[31] D. Fatta-Kassinos, M. I. Vasquez, and K. Kümmerer, "Transformation products of pharmaceuticals in surface waters and wastewater formed during photolysis and advanced oxidation processes - Degradation, elucidation of byproducts and assessment of their biological potency," Chemosphere, vol. 85, no. 5, pp. 693-709, 2011.

[32] S. Sortino, S. Petralia, F. Boscà, and M. A. Miranda, "Irreversible photo-oxidation of propranolol triggered by selfphotogenerated singlet molecular oxygen," Photochemical and Photobiological Sciences, vol. 1, no. 2, pp. 136-140, 2002.

[33] Q.-T. Liu and H. E. Williams, "Kinetics and degradation products for direct photolysis of $\beta$-blockers in water," Environmental Science and Technology, vol. 41, no. 3, pp. 803-810, 2007.
[34] P. Fernández-Ibáñez, F. J. De Las Nieves, and S. Malato, “Titanium dioxide/electrolyte solution interface: electron transfer phenomena," Journal of Colloid and Interface Science, vol. 227, no. 2, pp. 510-516, 2000.

[35] A. Mills and S. Le Hunte, "An overview of semiconductor photocatalysis," Journal of Photochemistry and Photobiology A, vol. 108, no. 1, pp. 1-35, 1997.

[36] F. J. Benitez, J. L. Acero, F. J. Real, G. Roldan, and F. Casas, "Bromination of selected pharmaceuticals in water matrices," Chemosphere, vol. 85, no. 9, pp. 1430-1437, 2011.

[37] K. Y. Foo and B. H. Hameed, "Insights into the modeling of adsorption isotherm systems," Chemical Engineering Journal, vol. 156, no. 1, pp. 2-10, 2010.

[38] K. V. Kumar and K. Porkodi, "Relation between some two- and three-parameter isotherm models for the sorption of methylene blue onto lemon peel," Journal of Hazardous Materials, vol. 138, no. 3, pp. 633-635, 2006.

[39] J. S. Piccin, G. L. Dotto, and L. A. A. Pinto, "Adsorption isotherms and thermochemical data of FDandC RED No 40 Binding by chitosan," Brazilian Journal of Chemical Engineering, vol. 28, no. 2, pp. 295-304, 2011.

[40] F. Méndez-Arriaga, J. Gimenez, and S. Esplugas, "Photolysis and $\mathrm{TiO}_{2}$ photocatalytic treatment of naproxen: degradation, mineralization, intermediates and toxicity," Journal of Advanced Oxidation Technologies, vol. 11, no. 3, pp. 435-444, 2008.

[41] V. Romero, N. de La Cruz, R. F. Dantas, P. Marco, J. Giménez, and S. Esplugas, "Photocatalytic treatment of metoprolol and propranolol," Catalysis Today, vol. 161, no. 1, pp. 115-120, 2011.

[42] L. A. Ioannou, E. Hapeshi, M. I. Vasquez, D. Mantzavinos, and D. Fatta-Kassinos, "Solar $/ \mathrm{TiO}_{2}$ photocatalytic decomposition of $\beta$-blockers atenolol and propranolol in water and wastewater," Solar Energy, vol. 85, no. 9, pp. 1915-1926, 2011.

[43] F. Méndez-Arriaga, S. Esplugas, and J. Giménez, "Photocatalytic degradation of non-steroidal anti-inflammatory drugs with $\mathrm{TiO}_{2}$ and simulated solar irradiation," Water Research, vol. 42, no. 3, pp. 585-594, 2008.

[44] H. Yang, T. An, G. Li et al., "Photocatalytic degradation kinetics and mechanism of environmental pharmaceuticals in aqueous suspension of $\mathrm{TiO}_{2}$ : a case of $\beta$-blockers," Journal of Hazardous Materials, vol. 179, no. 1-3, pp. 834-839, 2010.

[45] R. F. Dantas, O. Rossiter, A. K. R. Teixeira, A. S. M. Simões, and V. L. da Silva, "Direct UV photolysis of propranolol and metronidazole in aqueous solution," Chemical Engineering Journal, vol. 158, no. 2, pp. 143-147, 2010.

[46] C. Sahoo, A. K. Gupta, and I. M. S. Pillai, "Heterogeneous photocatalysis of real textile wastewater: evaluation of reaction kinetics and characterization," Journal of environmental science and health A, vol. 47, pp. 2109-2119, 2012.

[47] M. L. Wilde, W. M. M. Mahmoud, K. Kümmerer, and A. F. Martins, "Oxidation-coagulation of $\beta$-blockers by K2FeVIO4 in hospital wastewater: assessment of degradation products and biodegradability," Science of the Total Environment, vol. 452-453, pp. 137-147, 2013. 

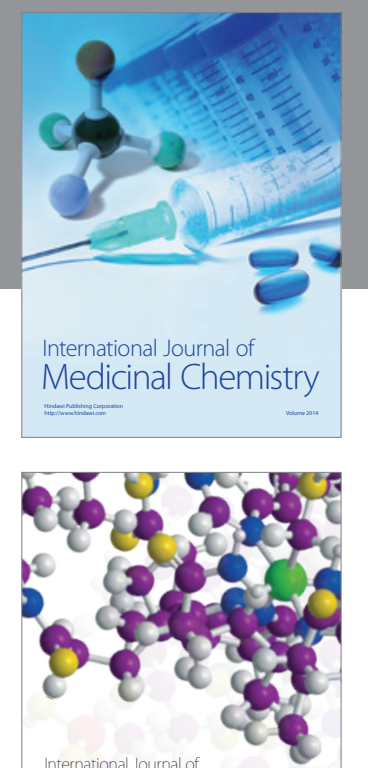

\section{Carbohydrate} Chemistry

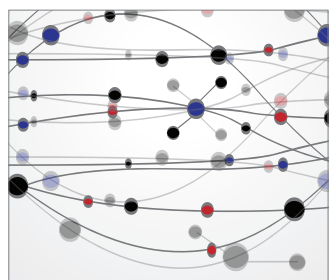

The Scientific World Journal
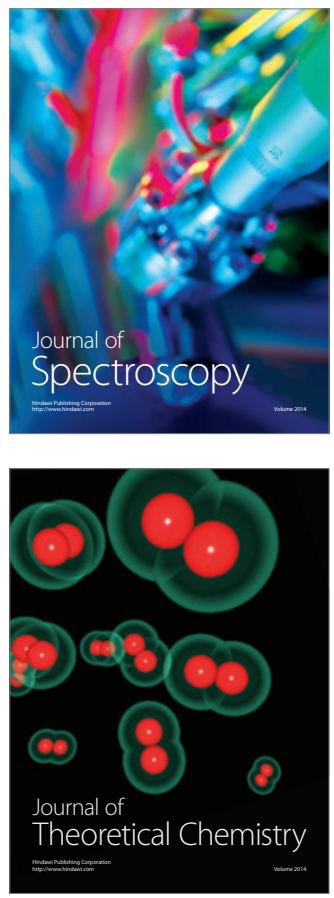
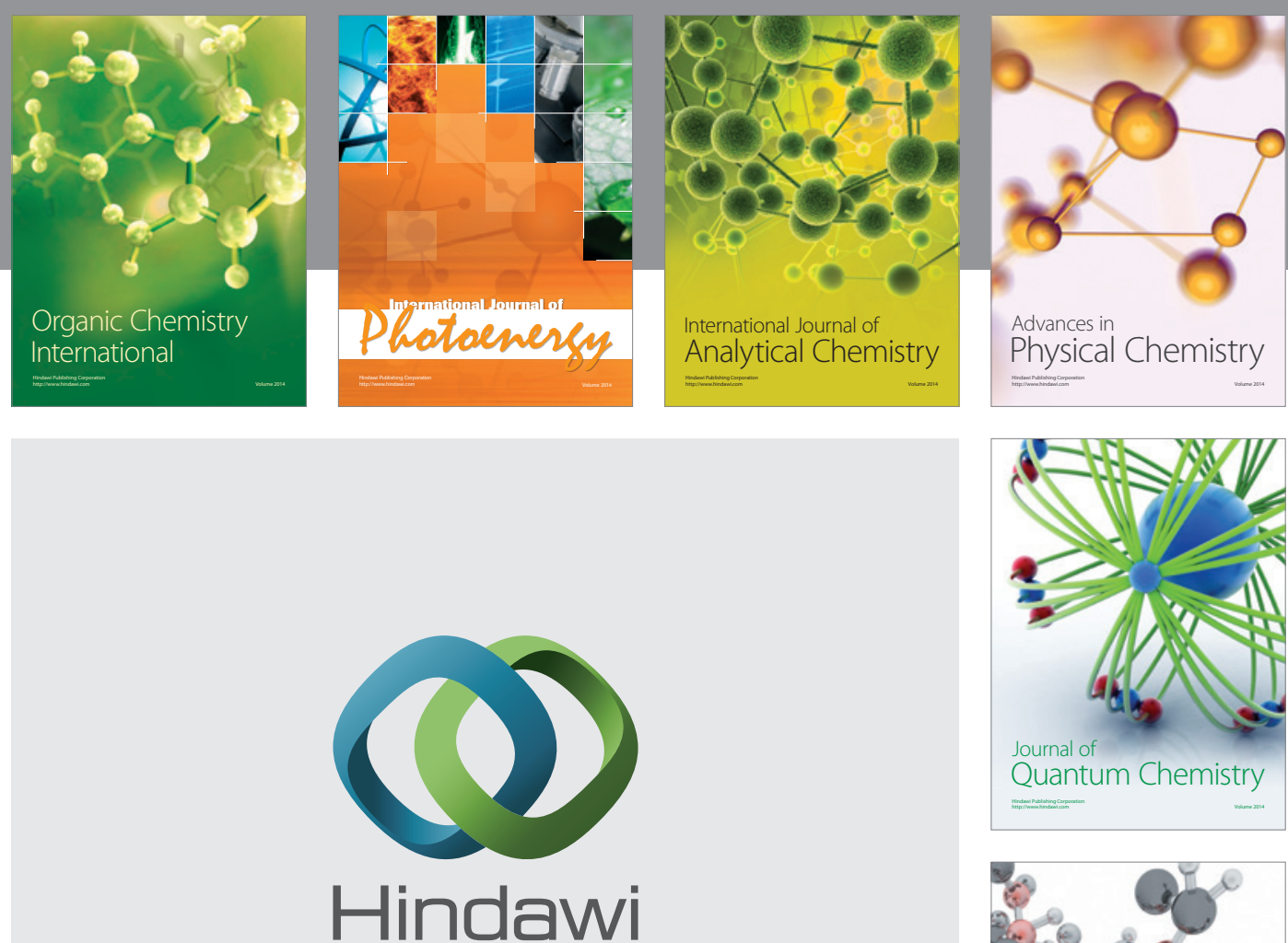

Submit your manuscripts at

http://www.hindawi.com

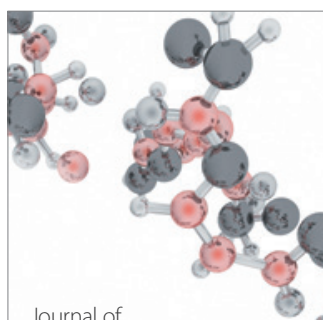

Analytical Methods

in Chemistry

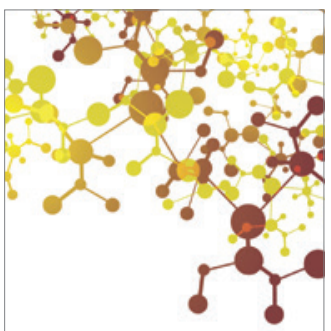

Journal of

Applied Chemistry

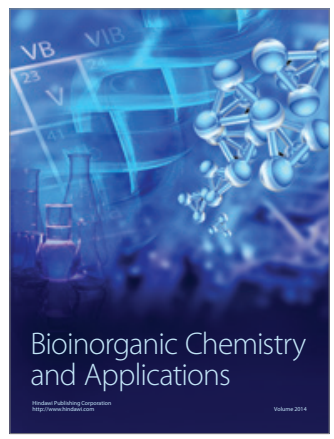

Inorganic Chemistry
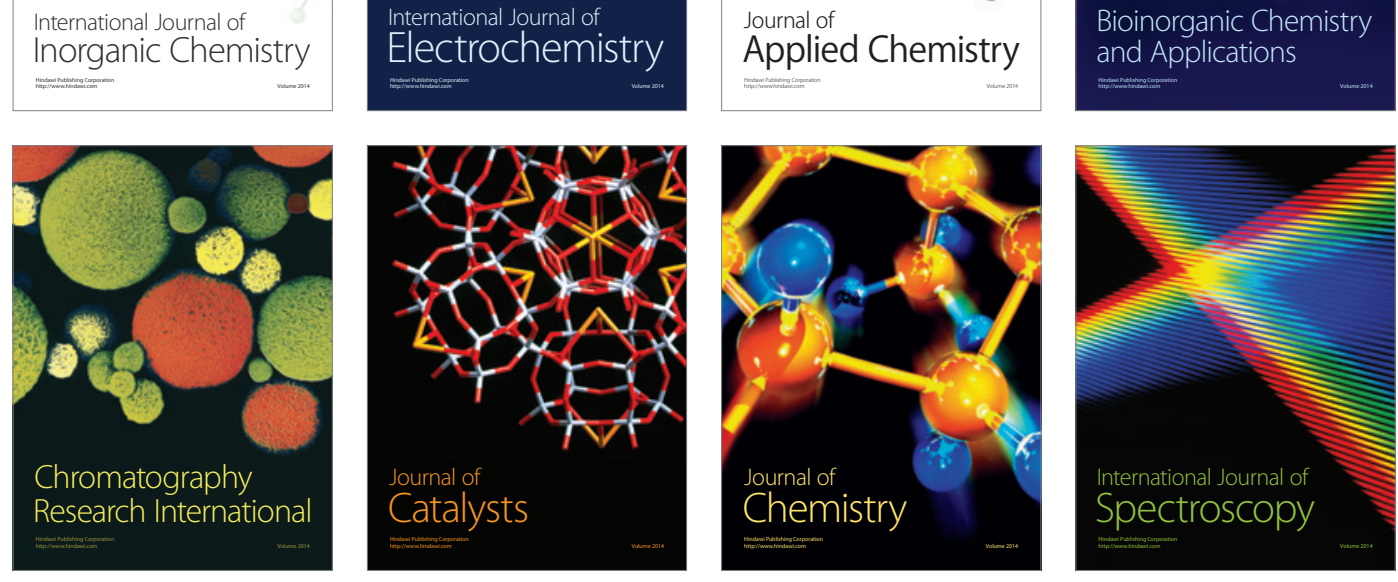